\title{
Discussion on Legal Identification of Parenthood in Surrogacy
}

\author{
Tianyi Xu \\ Criminal Justice College \\ East China University of Political Science and Law \\ Shanghai, China 201620
}

\author{
Ying Dai \\ Law School \\ Zhejiang University of Technology \\ Zhejiang, China 310012
}

\author{
Teng Li \\ Criminal Justice College \\ East China University of Political Science and Law \\ Shanghai, China 201620
}

\begin{abstract}
The emergence of surrogacy technology not only benefits mankind, but also breaks through the traditional natural reproduction mode, exerting a powerful impact on the rules of parenthood identification in the traditional civil law system. Considering that the traditional parenthood presumption principle of the triune sex, marriage and birth is no longer able to solve the problem in the identification of parenthood in surrogacy. When the parenthood of surrogacy children is determined, the law should break through the traditional idea of the delivery for the mother, and take the principle of the best interests for children as the starting point and end point and determine the surrogacy children as the legal parents by special legal procedures.
\end{abstract}

Keywords-surrogacy technology; legal identification of parenthood; best interests of children principle

\section{INTRODUCTION}

Since the birth of the world's first test tube baby in 1978, the total number of babies around the world has reached over 0.3 million by means of artificial reproductive technology. From a certain point of view, human beings are gradually playing the role of "God", but at the same time, the development of surrogacy technology has seriously affected social ethics and arouses people to think and discuss this topic widely. It is urgent to find a parenthood affirming method which not only can link up the parenthood identification rules of the traditional civil, but also can guide and regulate the development of surrogacy technology.

\section{THE LAW PREVUE OF SURROGACY AND THE} CURRENT SITUATION OF RELEVANT LEGISLATION IN CHINA

\section{A. Conception and Classification of Surrogacy}

Surrogacy refers to a way of bearing that surrogate motherhood is entrusted by surrogate husband and wife and the fertilized ovum is planted into the surrogate mother's womb, and the surrogate mother replaces the pregnant wife for gravidity and delivery.
According to whether there is blood relationship between surrogate mother and surrogate children, the surrogacy can be divided into the two types: gravidity surrogacy and gene surrogacy. The first, gravidity surrogacy, also named complete surrogacy, refers to that the surrogate mother does not provide her own eggs but the womb and replaces the others by implanting the fertilized eggs. There is no direct blood relationship between surrogate mother and surrogate children and the surrogate mother only acts as a mother of pregnancy delivery. The second, gene surrogacy, also named partial surrogacy or genetic surrogacy, refers to that the surrogate mother provides her eggs and the husband or the third party provides the sperm to conceive a surrogate mother by means of internal or external fertilization. However, because of the complexity of legal problems and ethical relation generated by gene surrogacy, in reality, whether the countries that open surrogacy services or prohibit surrogacy services have closed the door to the legalization of such surrogate patterns.

\section{B. A Review of the Current Legislation of Surrogacy in China}

At the present stage, there are no special laws to regulate the surrogacy technology in China. But, in 2001, the Ministry of Health issued Measures for the Administration of Human Assisted Reproductive Technology in the form of order by the Ministry of Health and the third article regulated that the application of human assisted reproductive technology should be carried out in medical institutions, for medical purposes, and in line with the national family planning policy, ethical principles and relevant laws and regulations. The buying and selling of gamete, zygote and embryo in any form is prohibited. Medical institutions and personnel are prohibited to carry out any form of surrogacy technology. It can be seen from the regulations that the Ministry of Health has made it clear that any form of surrogacy is prohibited. 
From the perspective of jurisprudence, the orders of Ministry of Health belong to departmental regulations, and departmental regulations are at the lowest order in the legal system. The seventy-first article of the legislation law of the People's Republic of China stipulates: "The State Council ministries, committees and the people's Bank, audit administration and the directly affiliated institutions with administrative functions can formulate regulations within the scope of authority of this department in accordance with the law and the administrative regulations of the State Council. The matters specified by the regulations of the department shall be subject to the administration regulation, decisions and orders of the enforcement of law or state council." There are no relevant laws, administrative regulations and State Council decisions and orders on surrogacy at the present stage in China.

Therefore, the Administrative Measures "make laws" by breaking through its limit of authority and has the suspicion of ultra vires. ${ }^{1}$ Moreover, the targets of Administrative Measures only are medical institutions and medical staff and have no substantive constraint force on surrogate couples and surrogate mothers, and the practical roles are somewhat embarrassing.

\section{LEGISLATIVE INVESTIGATION ON IDENTIFICATION OF PARENTHOOD IN SURROGACY FROM THE PERSPECTIVE OF COMPARATIVE LAW}

\section{A. Legislative Investigation on Surrogacy in Common Law System Countries}

Britain is one of the first countries to legislate on the surrogacy technology. In 1985, Britain published Surrogacy Agreement Act that comprehensively prohibits commercial surrogacy and surrogacy intermediary services and neither encourages or prohibits the non-commercial surrogacy. In 1990, Britain published Artificial Fertilization and Embryology to further standardize the surrogacy technology and define the rights and obligations of both parties, and established the human reproductive and embryo research licensing authority to control them. In 2009, Britain revised the Artificial Fertilization and Embryology, and the biggest highlight among them is to break the parenthood identification rules of the traditional civil and stipulates the identification standard of surrogacy parenthood.

The United States has no unified legislative regulation for the surrogacy technology because of the form of the state structure of federal system. In 1986, the two reverse judgments of "Baby M Case" triggered widespread discussion on surrogacy technology in the United States. Congress amended the Uniform Parentage Act in 2000 and 2002, and the revised acts provide detailed provisions on the effectiveness of surrogacy agreement and the identification of the children. ${ }^{2}$ As of 2009 , twenty-six states in the United States recognized the legality of surrogacy, and five states

${ }^{1}$ Zhang Yanling: Research on the Legislative Questions of Artificial Reproduction, Journal of Shandong University, 2006, 6 issue.

2 Jiang Bosheng: Law Status of Children of Artificial Insemination, The Journal of Law and Medicine, 2004, 11 Issue. and one special administrative region considered surrogacy to be the criminal, and the other nineteen states believed that the surrogacy agreement was invalid and prohibited the payment of any financial surrogacy service, but allowed free surrogacy.

\section{B. Legislative Investigation on Surrogacy in Civil Law Countries}

Germany has taken a firm negative attitude towards the surrogacy. In 1989, Germany made a law to deny the intermediary surrogacy in the revised Adoption Intermediary Law. On January 1, 1991, Germany passed the legal provisions of embryo protection in the implementation of Embryo Protection Law to deny the surrogacy technology. This act considers that surrogacy is the misuse of reproductive technology and surrogate mothers are considered legal mothers for surrogate children, however, the court may allow surrogate couples to adopt surrogate children through the adoption process, in accordance with the principle of the best interests of their children.

As another representative of the civil law countries, France also holds a negative attitude towards surrogacy services. In 1994, France formally adopted the Bioethics Law definitely to prohibit the surrogacy technology. This act stipulated that only the surrogate mothers could bring up surrogate children and the surrogate mothers who violated this provision would be punished. ${ }^{3}$ French Civil Code stipulates that any agreement that stipulates the birth or pregnancy for other's benefit will be null and void. The judicial practice in France believes that the surrogacy agreement violates the principle of public order that the human body is not allowed to be punished, so surrogacy is prohibited whether it is paid or unpaid.

\section{Comparison of the Current Situation of Surrogacy Legislation in the Two Main Legal Systems}

Generally speaking, common law system countries are more tolerant with the surrogacy technology and adopt the legislative attitude with the limited open. However, civil law countries are relatively conservative and tend to comprehensive prohibition. In the aspects of how to identify the parenthood in surrogacy, common law system countries pay more attention to the effectiveness of surrogacy agreements and affirm parenthood through the intermediary of state public power, in other words, the way of issuing the parental order by the court. For example, Britain stipulates that if the surrogate husband and wife obtain the parental right of surrogacy children, they should apply within six months after the birth of surrogacy children. At the same time, the surrogate mothers shall decide whether to retain the children within six weeks after the birth of the children. However, civil law countries adopt the traditional principle that "the delivery is the mother" because of the ban on surrogacy technology's attitude, and the surrogate husband and wife obtain the parental right by means of adoption. Germany is a typical representative. German Embryo

\footnotetext{
${ }^{3}$ Luo Jiezhen, the translation of French Civil Code (volume one), French Press, 2005 Edition, Page 260.
} 
Protection Act prohibits the surrogacy and Adoption Intermediary Law further stipulates that if the surrogacy occurs, according to the principle of the best interests for the children, the surrogate mother's baby could be adopted by the surrogate husband and wife.

\section{THE DOCTRINE AND PRINCIPLE OF IDENTIFICATION SURROGACY PARENTHOOD}

\section{A. Rules of Parenthood Identification in Traditional Civil Law}

There are three putative rules for the identification of parenthood in human society: First, one person only has one father and one mother after his birth. Unless there is some special legal fictions, this kind of parenthood and its rights and obligations accompanies his whole life; Second, the three processes of donor egg, pregnancy and gravidity concentrate on one mother and the delivery is the mother; Third, father is determined according to mother's marital relations. $^{4}$

Based on the natural reproductive state of inseparable delivery and consanguinity, the parenthood can be determined through the above three rules. Surrogacy differs from the natural reproduction, because of its special circumstances, and the single principle cannot reasonably determine the parenthood of surrogacy. First of all, the basis of surrogacy is the separation between delivery and consanguinity, and surrogate mother is not the heredity mother. The traditional deduction principle will cause many controversies on the determination of infant father. If the surrogate mother is married, the husband of surrogate mother will be presumed as infant father by the legitimacy presumption, and her husband can claim the denied legitimacy lawsuit with a reason that he has no blood relation with the infant, and the baby is in the state that his father can not be determined. If the surrogate mother is unmarried or the husband of surrogate mother claims the denied legitimacy lawsuit, the baby's father should be determined according to the claim of jus sanguinis and legitimation system. If the sperm of surrogacy comes from the husband of surrogate couple, the parents of surrogacy children may span two marital relations, which not only violates the original intention of surrogacy, but also goes against the healthy growth of surrogacy children. If the sperm comes from the donor, and the donor's original intention is to help others pregnant and has no meaning to be their father, so the law can not force to identify the donor as an infant father. Secondly, the traditional deduction principle ignores the legitimate demands of surrogate husband and wife and violates the purpose of surrogacy. The traditional parenthood presumption principle of the triune sex, marriage and birth is no longer able to solve the problem that the parenthood presumption is facing in artificial reproductive technology, but makes the simple problems more complex which is not conducive to the stability of marriage and family.

${ }^{4}$ Zheng Na: A Discussion on law status Identification of Surrogate Children, Legal System and Society, 2008, 9 Issue

\section{B. The Theory and Evaluation of Identification Surrogacy Parenthood}

According to the laws and regulations, judicial precedents and academic discussions of various countries, there are mainly four kinds of mainstream theories about the parenthood identification of surrogacy technology in the academia.

1) Bloodlines theory: Bloodlines theory is also called gene theory. The theory is based on the biological genetic relationship between parents and children, which is the basis of parenthood, that is, egg donor is the mother and the donor is the father. The judgment of rights and obligations of parents and children follows the traditional ethics of "carrying on the family line" and pays attention to the blood relationship.

With the progress of human civilization, the theory has gradually been unable to meet the changing social situation. In the laws of various countries, "natural blood relation" is the embodiment of bloodlines theory and the "fictitious relative" is a complement to the bloodlines theory. Obviously, artificial reproductive technology is highly developed. If the bloodlines theory is determined as the standard of the relationship between parents and children, it will lead to great confusion.

2) Delivery theory: The delivery theory is also named womb theory. This theory is based on the traditional principles of civil law that "the delivery is the mother", which shows respect for the hard work of surrogate mothers. Some domestic scholars believe that "delivery theory" is the best way to determine the legal mother for the surrogate children, and it should give the right to surrogate mother for the reward of pregnancy delivery. ${ }^{5}$ However, the author believes that the purpose of surrogate mother is not to obtain parental rights. "The theory of parental rights return" can not achieve the purpose of providing the protection or compensation for surrogate mother but violate the will of surrogate mother and add the burden to surrogate mother. Moreover, "delivery theory" does not conform to the purpose of surrogacy. If surrogate couples want to obtain the parental rights, they should experience the adoption proceedings, regardless the increased cost of both parties, and the instability of fictitious relative is not conducive to the stability of marriage and family and the healthy growth of surrogate children.

3) Contract theory: This theory is also called purpose theory. The definition of parenthood is in accordance with the parental rights definition clause in the surrogate contract, that is, law will definite the surrogate couples as the legal parents for the infant.

The advantage of contract theory is that both parties reach an agreement on the basis of equality and voluntariness and the cost of parental confirmation is low and the resistance is small. The theory for the identification

\footnotetext{
5 Zhang Yanling: Research on the Legislative Questions of Artificial Reproduction, Journal of Shandong University, 2006, 6 issue.
} 
of parenthood confirms to the purpose of surrogacy, however, the central point of an argument of contract theory in theoretical cycle is whether the identification of parenthood belongs to the scope of law of descent and they lead the autonomy will to the scope of law of descent which is based on the imperative law, and whether the practice of the autonomy will to fully deliver the parenthood to the parties hereto is contrary to the seriousness of law of descent? At the same time, "contract theory" is also facing the following problems: if the surrogate couples dissolve their marriage during the pregnancy of surrogate mother, how to solve the problems that one party wants to terminate surrogacy and the other party insist on continuing the performance of the contract? If both parties of surrogate couples want the surrogate mother to terminate pregnancy because of some special reasons, and surrogate mother refuse to stop pregnancy or because of physical reasons, how should it be resolved? If the surrogate mother violates the contract to refuse to deliver the baby, whether the surrogate couples can require the surrogate mother to perform her obligations by some methods of compulsory execution? Can the surrogate children be used as the object of compulsory execution?

4) The best interests of children theory: The best interests of children theory put the interests of children in the first place as the starting point and end point for the surrogacy parenthood identification. According to this theory, children as the independent individuals should be protected by the law and they should make parental identification by the public power of the state, so as to ensure the maximization of the interests of the children. However, the best interests of the children themselves are difficult to have a unified evaluation criterion, and judges need to review the every case involved with the interests of children. Its cost of justice is relatively larger and the requirements for the judge level are also higher.

\section{The Principle of Surrogate Parenthood Identification}

The four mainstream theories have their own rationality, but none of them is solely suitable for the criterion of surrogate parenthood. According to the legislative rule of surrogate parenthood identification in many countries, the following principles are mainly applied to guide parenthood identification in surrogacy.

1) The principle of the best interests of children: As a typical representative of this principle, Britain pays attention to the best interests of children when the parenthood is identified. When the dispute of parental rights arises, Britain regards the protection of children's interests as the starting point and end point and as the first principle for surrogate parenthood identification.

2) The principle of public power intervention: In the aspect of surrogacy technology, the United States pursues "the principle of autonomy of will of the limited parties" and the surrogate contract must be owned legal effects by the court hearing, and the surrogate contract is not suitable for compulsory. And Britain sets up Human Reproduction and Embryology Research Licensing Authority to supervise the behavior of surrogacy. These two methods are able to investigate the qualification of surrogate couples, surrogate mothers and surrogate agencies before surrogacy and provide relief for potential legal disputes after the event.

3) The principle of linking up with traditional civil law: Civil law countries forbid the any forms of surrogate service, and "the principle that the delivery is the mother" in the traditional civil law is applicable when the legal parents of surrogate children are identified. Germany adopts the combination of "the principle of the best interests of children" and "the principle that the delivery is the mother" to appropriately adjust the identification results of parenthood in surrogacy. In the aspect of surrogate parenthood identification, Britain also is consistent with the identification rules in traditional civil law, but Britain determinates the surrogate couples as the legal parents for babies by the adoption process after the event. ${ }^{6}$ Although surrogacy technology has caused great impact on the parenthood identification in traditional civil law, the legislation of various countries still strives for the stability of traditional civil law. In the case of not breaking the original rules, the adoption of other auxiliary principles to adjust the identification results in order to achieve stability in marriage and family.

\section{LEGAL CONSTRUCTION OF SURROGATE PARENTHOOD IDENTIFICATION SYSTEM IN CHINA}

\section{A. The Followed Principles for Surrogate Parenthood Identification}

In the construction of surrogate parenthood identification system, it should be considered to confirm to the parenthood identification rules of other assisted reproductive technology, and should make full use of the existing judicial resources, to maintain the stability of marriage and family and ensure the healthy growth of surrogate children as far as possible.

Considering that there are no surrogate parenthood identification rules in our existing legislation and considering the various theories and principles in academic circles and their advantages and disadvantages, the author believes "the principle of best interests of children" should be regarded as the first principle for the legal parents of surrogate children identification when the surrogate parenthood is identified. The court should investigate the conditions, such as legal parents' psychological anticipation for child-rearing, their age, occupation, health status, economic ability and living conditions and the upbringing environment of their surrogate children. If the surrogate mother is judged as legal mother for baby, the parenthood identification should be carried out in accordance with traditional "the principle that the delivery is the mother". If surrogate couples are judged as legal parents for baby, the

\footnotetext{
${ }^{6}$ Liang Huixing edited Civil and Economic Laws (Volume 8), Law Press China, 1997 Edition, Page 77.
} 
parental rights should be given to surrogate couples by traditional adoption procedure. The greatest advantage for this kind of identification method is that it not only can ensure the maximization of children's interests, but also can make full use of the existing legal system and judicial resources and reduce the impact on the traditional civil law theory.

\section{B. Legislative Prospect of Surrogate Parenthood in China}

According to the trend of international legislation, surrogacy technology experiences the process of "from absolute prohibition" to "open non-commercial surrogacy". The common law countries are in the front of surrogacy legislation, while the civil law countries are afraid that surrogacy technology will damage the stability of marriage and family, so they prohibit any forms of surrogacy technology. However, it is easy to dredge but difficult to block for Da Yu to address the flood. The system vacancy and supervision vacancy leads to the safeguard of the rights and obligations, and this kind of total negative attitude will not only can not regulate the behavior of surrogacy, but also lead the surrogate service activities to transfer to the black market. Especially in the problems of surrogate parenthood identification, the law does not provided clear identification rules. When such cases occur, the judge can not invoke any laws and regulations to support his judgments, and the actual judgments in different regions even appear quiet different and contradictory phenomena, which further leads to instability in marriage and family.

According to the legislation status and theories of different nations, the author thinks that it can combine "the principle of the limited autonomy of will" with "the principle public power intervention" as the judgment standard for the legal parents of surrogate children in the construction of the surrogate parenthood identification rules in China, and we shall make adjustments and remedies for other exceptions supplemented by "the principle of best interests of children" in the actual identification.

The whole process of surrogate parenthood identification can be divided into two parts, and the specific procedures are as follows.

First, the court will examine the qualifications of both surrogate parties before the event and the both parties are allowed to carry out surrogacy at the designated medical institution upon examination. After the birth of child, the court shall issue the parental rights order to directly confirm the surrogate couples as the legal parents for the baby.

Second, if the both surrogate parties have objections to the problems of parental rights, any party can file a lawsuit to the court. Then the court will make the second review for the both surrogate parties based on the "principle of best interests of children", when considering the best interests of children, the following factors should be combined: legal parents' psychological anticipation for child-rearing, their age, occupation, health status, economic ability and living conditions and the upbringing environment of their surrogate children. Finally, the court confirms the baby's legal parents.
The above methods of judging surrogate parenthood are mainly based on the following points.

Firstly, it is conducive to achieve the purpose of surrogacy. As a kind of artificial reproduction technology, the purpose of surrogacy is to help the couples who are unable or unfit to have children to obtain a blood related child and surrogacy is essentially a kind of cooperation action. According to Mill's "no harm principle", the nations shall not interfere with individual actions if they do not damage the public interest. ${ }^{7}$ Therefore, as long as the surrogacy does not damage the public interest and lawful rights and interests of others, the law shall respect the autonomy of will of the two parties. However, in view of the fact that identity cognizance belongs to the scope of compulsory law, it is contrary to the seriousness of the law that all the things are negotiated with parties to identify and not conducive to the protection of children's interests. Therefore, through the method of intervention of the national public power, the court shall examine the qualifications of both parties and issue the parental rights order to confirm the surrogate couples as the legal parents for the baby. This method not only maintains the seriousness and stability of the traditional parenthood identification, but also achieves the purpose of surrogacy.

Secondly, it is conducive to protect the interests of children and both parties. In the original intention of surrogacy, the surrogate couples have a strong desire to support their babies, while surrogate mothers do not have the will to become a legal mother. If the identification rules of traditional civil law that "the delivery is the mother" are observed, it will undoubtedly make the simple things become complex and violate the will of both surrogate parties. Compared with the surrogate mother, the surrogate couples have more will and preparation to be the parents. Complete family environment and dual parenting is conducive to the healthy growth of children and conforms to the interests of children. ${ }^{8}$ If the surrogate mother has the feelings towards the surrogate children and is unwilling to give the baby to the surrogate couples, the court shall also determine the legal parents based on the best interests of the baby.

Finally, it is conducive to the unity and stability of the artificial reproductive law. The argument of surrogate parenthood identification is united with the parenthood identification standard of other artificial reproductive technology, that is, it identifies the infertile couples as the legal parents of babies born under artificial reproductive technology, which avoids the complication of standards and reduces the impact on our existing civil law system.

\section{CONCLUSION}

In our country, people will feel a pity for the lack of legislation on surrogacy. The law, as the basic code of

\footnotetext{
${ }^{7}$ Liao Yaci: Study on Artificial Reproduction and Legal Morality Problems, China Legal Publishing House. 1995 Edition, Page 129.

${ }^{8}$ Lin Xiuxiong: Research on Marriage Law, China University of Political Science and Law Press, 2001, volume 1, Page 151.
} 
conduct to maintain social behavior, can not ignore or put aside this phenomenon because of the complicated problems. We should connect with the practice closely, have a positive attitude to deal with, take precautions and nip in the bud. Therefore, the author calls for legislation to be followed up step by step, from the present comprehensive prohibition to the limited opening, and our country shall recognize the legitimacy of surrogacy. The scope of the surrogate behavior shall be limited and the intermediary agency for the implementation of surrogate services shall be supervised. The law shall make clear about the rights and obligations of all parties and provide practical legal remedies in case of disputes.

\section{REFERENCES}

[1] Yu Yanman. Original Theory of Relative Law [M], Beijing: Law Press, 2007 Version

[2] Fei Xiaotong. Rural China and Fertility System [M], Beijing: Peking University Press, 2000 Version

[3] Li Zhiqiang. Adjustment of Civil Law on Surrogacy [J], Journal of Shanxi Normal University (Social Science Edition) 2011, (3): 21-25

[4] Yu Jing. Exploration on Reasonable Application of Surrogacy Technology [J], Hebei Law Science, 2013(1): 125-130

[5] Xiong Jinguang, Zeng Xiangxin. Analysis on Belonging of Parental Right under the Background of Surrogacy Technology: Take the National First Case of Dispute in Guardianship Caused by Surrogacy [J], Public Administration and Law, 2017, (6): 95-103

[6] Yuan Quan, Luo Yingyi. Several Problems of International Private Law Involved in Identity of Parenthood Caused by Cross-border Surrogacy [J], Chinese Review of International Law, 2016, (6): 104116. 